Article

\title{
Strategic Options for Campus Sustainability: Cluster Analysis on Higher Education Institutions in Japan
}

\author{
Maki Ikegami ${ }^{1, *}$ and Bart Neuts ${ }^{2}(\mathbb{0}$ \\ 1 Sustainable Campus Management Office, Hokkaido University, Sapporo 060-0808, Japan \\ 2 Department of Earth and Environmental Sciences, KU Leuven, 3001 Heverlee, Belgium; \\ bart.neuts@kuleuven.be \\ * Correspondence: ikegami@osc.hokudai.ac.jp
}

Received: 25 February 2020; Accepted: 20 March 2020; Published: 23 March 2020

\begin{abstract}
This study evaluates campus sustainability initiatives in Japanese higher education institutions over the 10-year period since a related important political declaration was made. Our findings show that implementation of sustainability actions was still largely lacking. This is one of the first extensive empirical studies on Japanese higher education institutions to examine data related to institutions that conform with the Assessment System for Sustainable Campus (ASSC). Our study aimed to identify key factors that promote robust campus sustainability among Japanese institutions. Our research question was "What are the strategic options of institutions that conform with ASSC?" We aimed to determine which fields best prompt Japanese higher education institutions to initiate campus sustainability initiatives. We applied cluster analysis to 42 cases collected by ASSC toward identifying groups of institutions with different strategic options. The analysis identified four groups: "lagging-behind", "asset-driven", "top-of-the-class", and "networkers" clusters. An important finding of this study was that the asset-driven and networkers clusters showed significant positive scores with respect to asset management and networking. Our survey about institution size revealed two major findings: (1) despite the general dependency of campus sustainability on resources, both large and small institutions were capable of attaining the top-of-the-class cluster by adopting a holistic strategy; (2) small institutions are able to implement campus sustainability initiatives by focusing on asset management or networking.
\end{abstract}

Keywords: campus sustainability; Japanese higher education institution; strategic option; cluster analysis; institution size

\section{Introduction}

\subsection{Concept of Campus Sustainability}

Today, the social responsibility of higher education institutions in contributing to a sustainable society is commonly recognized. Since the 1970s, political actions have been implemented to integrate environmental education into the curriculum of higher education institutions [1,2]. In addition to such political initiatives, actions to promote environmental efficiency in campus operations became evident in the 1990s-mainly in North American universities and subsequently in European ones. Those actions were influenced by policy actions or declarations undertaken by international meetings on the environment [3,4]. Brinkhurst et al. [5] identified the Stockholm Declaration of 1972 [1] and Talloires Declaration of 1990 [6] as important events in this regard.

Triggered by environmental initiatives, the actions executed by higher education institutions toward a sustainable society have evolved over recent decades. However, Habib and Ismaila [7] claimed that conventional approaches, such as traditional practices and regulations to sustainability 
issues, were reactive, project-based, and conducted in an ad hoc manner. The authors maintained that it is necessary to develop a systematic, holistic approach to university environmental management systems, public participation, and social responsibility and that sustainability should be promoted in teaching and research [7]. Similarly, Waas et al. [8] concluded that curriculum development, research, partnership with other sectors, and physical operation were still insufficient. According to Habib and Ismaila [7], university campuses should be models, serving as community centers for promoting sustainability and supporting the concept that high education institutions are important symbols of sustainability. This point was echoed in the Sapporo Sustainability Declaration, which was adopted in the first G8 university summit to be held in Japan, in 2008 (see Section 1.2) [9].

These responsibilities of higher education institutions are currently summarized in a concept termed the "sustainable university" or "sustainable campus" (campus sustainability). The concept of campus or university sustainability can be approached and defined in multiple ways; however, different expressions indicate largely overlapping dimensions. Cole [10] defined a sustainable campus as follows: "A sustainable campus community acts upon its local and global responsibilities to protect and enhance the health and well-being of humans and ecosystems. It actively engages the knowledge of the university community to address the ecological and social challenges that we face now and in the future." According to Velazquez et al. [11], "A sustainable university is a higher educational institution, as a whole or as a part, that addresses, involves and promotes, on a regional or a global level, the minimization of negative environmental, economic, societal, and health effects generated in the use of their resources in order to fulfill its functions of teaching, research, outreach and partnership, and stewardship in ways to help society make the transition to sustainable lifestyles." Habib and Ismaila [7] maintained, "A sustainable university campus should be a healthy campus environment, with a prosperous economy through energy and resource conservation, waste reduction and an efficient environmental management, and promotes equity and social justice in its affairs and exports these values at community, national and global levels."

From these definitions, it is evident that a general concept of a sustainable campus has four dimensions: environmentally efficient operations; sufficient well-being for internal and external campus users; education and research on sustainability; and social engagement toward a sustainable society. In this paper, we define the concept of campus sustainability as shown in Figure 1.

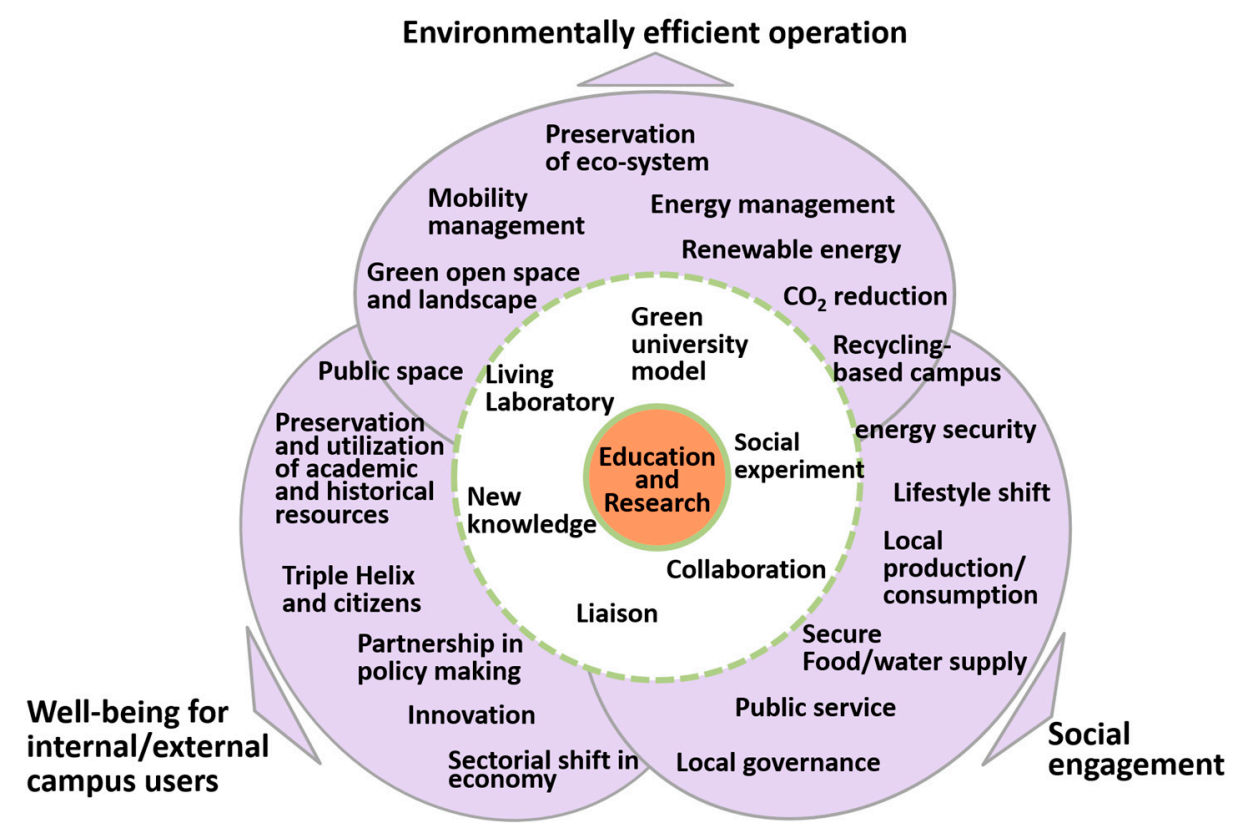

Figure 1. Concept of campus sustainability. 
The number of studies on campus sustainability in North America and Europe has been increasing. Originally, those studies mainly focused on the conceptualization of sustainable campuses or the assessment framework; however, more empirical studies analyzing specific cases have also become prevalent for those regions [8,12-15]. With respect to Japanese higher education institutions, studies have examined environmental management, education for sustainable development (ESD), and curricula for sustainability science [16-20]; they partially covered the four dimensions of the concept of the sustainable campus depicted in Figure 1. Almost no empirical studies in Japan have analyzed how institutions practice the sustainability initiative based on the whole concept of campus sustainability.

The present investigation is one of the first extensive empirical studies on sustainable campuses of Japanese higher education institutions to examine participant data with respect to the Assessment System for Sustainable Campus (ASSC) (see Section 2.1). This study aimed to identify the crucial factors for promoting Japanese campus sustainability in a more robust manner. It is necessary to analyze institutions that conform with ASSC to determine their strategic choices and the fields where they are successfully pursuing the concept of campus sustainability. Accordingly, we applied cluster analysis to identify groups of Japanese higher education institutions with different strategic options according to their main areas of focus. The results of this analysis will provide useful guidance for other Japanese institutions initiating actions toward a sustainable campus. Materials and methods of analysis we applied are explained in Section 2, including the details of ASSC. The results of cluster analysis follow in Section 3. The last section, Section 4, is devoted to the discussion about the guidance for Japanese campus sustainability.

\subsection{Research Background}

The earliest move in Japan toward sustainable campuses began as a project to establish an environmental management system on campus. Chiba University was one of the pioneer higher education institutions in Japan: it initiated a project in 1999 to acquire ISO 14001. Ueno et al. [21] stated that the project was launched to incorporate students and the local community into the environmental and facility management on campus. Chiba University succeeded in acquiring ISO 14001 in 2005; it established an environmental student committee to maintain that standard.

Another important action for environmental management was Eco University Ranking, which was developed by the student nonprofit organization Eco League. One section of Eco League, Campus Climate Change (CCC), operated Eco University Ranking from 2009 to 2014. The purpose of Eco University Ranking is to evaluate energy consumption, greenhouse gas emissions, research activities for global warming, and university social responsibilities [22]. For a while, the tool was successful because of its clear quantitative results and ranking system; over 300 Japanese universities have used that assessment. Clearly, Eco University Ranking focuses only on challenges on campuses for environmental impact reduction. In 2015, CCC discontinued use of that tool.

After those campus management actions were initiated in 2005-2014, ESD was strongly promoted by Japan's Ministry of Education, Culture, Sports, Science and Technology (MEXT); it did so under a United Nations campaign called Decade of ESD. The governmental initiative for ESD provided crucial support for Japan's higher education institutions. The initiative was successful in activating ESD movements. However, after a while, it became evident that the initiative fostered institutional dependence on subsidies; among the institutions concerned, the development of leadership for sustainability was lacking [18]. Similarly, Kitamura and Hoshii (2010) found that, on the whole, there was a lack of shared recognition of ESD or sustainability among institutions [19]. The Integrated Research System for Sustainability Science (IR3S) was another movement funded by MEXT (2005-2009) to enhance research and curriculum development of sustainability science $[16,17]$. That program was coordinated by the University of Tokyo with the collaboration of Kyoto University, Osaka University, Hokkaido University, and Ibaraki University. However, when MEXT funding ceased, all those universities reformed or closed their core sections of IR3S. These ESD or sustainability science initiatives in Japanese higher education did not lead to a holistic concept of campus sustainability. 
In around 2008, researchers from architecture and urban planning eventually began referring to the concept of the sustainable campus. That was prompted by an important political achievement: the Sapporo Sustainability Declaration (SSD) [9]. The University of Tokyo and Hokkaido University led the first G8 University Summit in 2008; there, SSD was adopted by 35 universities and institutions from 14 countries in six continents. With SSD, eight principles are affirmed. They include the following: "3. The responsibility of universities to provide timely solutions and closely coordinate with policy-makers"; " 4 . The need to restructure scientific knowledge that addresses socioeconomic as well as environmental issues", and "8. The function of the university campus as an experimental model to test new sustainability-relevant knowledge in a social context" [9]. In line with those statements, researchers in architecture and urban planning recognized the need to develop an assessment tool for sustainable campuses in Japan based on the social, environmental, and financial aspects of higher education institutions [23]. Their need for such an assessment system was subsequently met by the Office for Sustainable Campus of Hokkaido University in 2013; that office developed the ASSC (see Section 2).

SSD prompted the founding of a sustainable campus office in the University of Tokyo (2008) and Hokkaido University (2010); they were followed by Kyoto University (2013) and Osaka University (2017). The Campus Sustainability Network in Japan (CAS-Net JAPAN) — the first and, so far, only Japanese sustainable campus network-was established in 2014. However, CAS-Net JAPAN has not been successful in attracting member institutions: as of 2019, only 41 of over 800 higher education institutions in Japan were members. Opening a sustainable campus office is a rarity in Japan; among its large-scale universities, no institution has a primary sustainability focus—even in 2019 [24]. This weak trend among Japan's higher education institutions 10 years after SSD was quite different from the situation in Europe and North America. For example, over a 10-year period, Canada had robust growth with respect to campus sustainability [25].

The above developments underline the importance of identifying crucial factors, i.e., accelerators, for enhancing campus sustainability among Japan's higher education institutions. It is clear that institutions that conform with ASSC would be suitable for analysis: they were pioneers of sustainable campuses in Japan. Each of those institutions has chosen strategic options; their actions were evaluated by ASSC to see how they practiced campus sustainability. Our research question in this paper can be summarized as follows: What are the strategic options of institutions that conform with ASSC? The answers to that question should indicate the fields that Japanese higher education institutions should focus on to establish sustainable campus actions.

\section{Materials and Methods}

\subsection{Assessment System for Sustainable Campus}

Shriberg [12] said, "Assessment tools are important in operationalizing charters and policy statements about sustainability in higher education such as Talloires Declaration in 1990 [6], Halifax Declaration in 1991 (see Lester Pearson Institute for international Development, 1992), Kyoto Declaration in 1993 (International Association of Universities), and Copernicus Charter in 1994 (CRE-Copernicus, 1994)." Shriberg [12] also referred to Roorda [26]: "Although these documents contain important guidelines for education, none of them offers concrete prescriptions on an operational level for what higher education should do exactly in order to contribute maximally to sustainable development." Shriberg [12] also added this: "Assessment tools can help alleviate this problem through identification of best practices and focusing campus efforts on continual improvement. These tools also facilitate communication of progress within and across institutions, which is a key to mutual success in moving toward the ambitious and amorphous target of sustainability in higher education."

In line with this discussion of previous research, Hokkaido University in 2013 developed the first assessment system for sustainable campuses (implementation began in 2014) applicable to Japan's higher education institutions: ASSC. The system involves 170 assessment criteria, which cover four 
dimensions of the concept of sustainable campus (see Section 1.1). The criteria are categorized into four fields: I, Management; II, Education and Research; III, Environment; and IV, Local Community. Hokkaido University and CAS-Net JAPAN have collaborated in implementing ASSC: an online system was developed by Hokkaido University; CAS-Net JAPAN invited higher education institutions to respond to ASSC. A respondent institution can complete all the assessment details online; after fulfilling all the criteria, their results appear automatically on their account's online page. In all, 59 cases were collected by ASSC from 2014 to 2017. To determine which areas are appropriate for Japanese institutions for embarking on sustainable campus actions at an inaugural stage, we analyzed the strategic options of institutions that responded to ASSC.

\subsection{Methodology}

The original dataset of ASSC respondent universities consisted of 59 cases: nine institutions provided multiple responses to the questionnaire. To adhere to respondent independence, we used only the most recent answers for each university, which resulted in 42 cases for analysis. The questionnaire consisted of 170 assessment criteria, which covered 26 distinct areas in four fields: I, Management; II, Education and Research; III, Environment; and IV, Local Community. We based our analysis on the composite scores of the assessment criteria (i.e., the 26 areas). We aggregated the scores; otherwise, the number of variables would have exceeded the number of cases and because the indicators were only measured on one-, two-, or three-point scales without interval qualities. An overview of the area variables, the measurement scale, and descriptive sample statistics appears in Table 1.

Table 1. Overview of assessment areas of the Assessment System for Sustainable Campus (ASSC).

\begin{tabular}{|c|c|c|c|c|}
\hline Field & Area & $\begin{array}{l}\text { Number of Assessment } \\
\text { Criteria Covered }\end{array}$ & Scale & $\begin{array}{c}\text { Mean } \\
\text { (Std. Dev.) }\end{array}$ \\
\hline \multirow{8}{*}{ I } & 1.1 Policy and overall plan & 4 & $0-12$ & $6.79(3.979)$ \\
\hline & 1.2 Organization to consider sustainability & 9 & $0-17$ & $10.02(5.367)$ \\
\hline & 1.3 Financial resource management & 8 & $0-12$ & $5.24(3.176)$ \\
\hline & 1.4 Asset management & 5 & $0-12$ & $10.07(2.123)$ \\
\hline & 1.5 Facility management & 6 & $0-18$ & $12.10(5.193)$ \\
\hline & 1.6 Network to enhance sustainability & 2 & $0-4$ & $1.40(1.578)$ \\
\hline & 1.7 Personnel training & 4 & $0-6$ & $1.74(2.142)$ \\
\hline & 1.8 Procurement and contracts & 5 & $0-5$ & $2.88(1.273)$ \\
\hline \multirow{3}{*}{ II } & 2.1 Education & 6 & $0-16$ & 8.09 (3.348) \\
\hline & 2.2 Research & 7 & $0-11$ & $7.17(3.512)$ \\
\hline & 2.3 Students & 3 & $0-5$ & $2.93(1.840)$ \\
\hline \multirow{10}{*}{ III } & 3.1 Ecosystem & 8 & $0-24$ & $6.12(7.677)$ \\
\hline & 3.2 Land & 7 & $0-16$ & $7.50(4.743)$ \\
\hline & 3.3 Public space & 5 & $0-15$ & $6.98(4.841)$ \\
\hline & 3.4 Landscape & 2 & $0-6$ & $3.93(2.053)$ \\
\hline & 3.5 Waste & 5 & $0-9.25$ & $5.98(2.550)$ \\
\hline & 3.6 Energy and resources & 18 & $0-40.25$ & $15.53(8.262)$ \\
\hline & 3.7 Basic equipment & 6 & $0-14$ & $8.52(5.052)$ \\
\hline & 3.8 Facilities & 11 & $0-17$ & $6.63(3.014)$ \\
\hline & 3.9 Transportation & 11 & $0-17$ & $7.24(4.903)$ \\
\hline & 3.10 Use of historical assets on campus & 4 & $0-4$ & $2.10(1.650)$ \\
\hline \multirow{5}{*}{ IV } & $\begin{array}{l}\text { 4.1 Collaboration between industry, academia, } \\
\text { and government }\end{array}$ & 8 & $0-21$ & $14.86(6.111)$ \\
\hline & 4.2 Community service & 9 & 0-19 & $13.90(4.982)$ \\
\hline & 4.3 Dissemination of information & 2 & $0-2$ & $1.17(0.853)$ \\
\hline & 4.4 Disaster prevention & 11 & $0-18$ & $13.061(3.89)$ \\
\hline & 4.5 Role of university after disaster occurrence & 4 & $0-8$ & $3.02(2.454)$ \\
\hline
\end{tabular}

A preliminary analysis could investigate the average scores per area to identify areas where sustainable management policies were still lacking. However, such an analysis would be complicated by the fact that composite variables-comprising greater numbers of assessment criteria (e.g., Energy and resources, Facilities, Transportation in Table 1)—would inevitably be lower. Furthermore, such an analysis would fail to account for individual differences, as identified by the respective standard 
deviations. Though not providing a true solution to the first problem, cluster analysis could address the second problem: it could be designed to specifically identify differences among clusters.

According to the research question presented in Section 1.2, the main aim of our cluster analysis was to identify groups of Japanese universities with different strategic options according to their main areas of focus. Among the many clustering techniques available, we selected hierarchical clustering and a k-means partitioning method. The two approaches follow different trajectories to derive a cluster solution; thus, comparison between them can lend validation to the constructed clusters. It is well established that hierarchical clustering follows an agglomerative approach: clusters are consecutively formed from objects, starting with as many clusters as there are objects and sequentially merging objects according to similarities. In this paper, the measure of similarity used was the squared Euclidean distance. By contrast, the k-means cluster algorithm employs within-cluster variation as a measure for the formation of homogeneous clusters. The process first assigns objects randomly to a specified number of clusters, reassigning objects to minimize within-cluster variation [27]. Finally, to establish the relevance of the cluster solution, we performed a discriminant function, using the identified cluster memberships as a grouping variable. Discriminant analysis aims for a linear combination of predictor variables that best explains the differences in cluster memberships.

\section{Results}

Before starting the cluster analysis, we standardized all variables to account for differences in scale. We conducted all statistical procedures on these standardized variables. As a first step in the cluster analysis, we analyzed correlations among the clustering variables: strong correlation leads to an overrepresentation of the variables in the final clustering solution [27]. All bivariate correlations fell well below the 0.9 threshold, indicating no potential collinearity issues. There is no clear consensus on whether to opt for a partitional (k-means) or hierarchical clustering method; thus, we pursued both methods, which also served as a test of cluster stability. Since k-means clustering requires a priori selection of cluster numbers, we used the NbClust package in $\mathrm{R}$ to calculate a number of different indexes [28], as indicated in Table 2.

Table 2. Selection of cluster size indexes.

\begin{tabular}{cccc}
\hline Index & Reference & Index Value & Suggested Number of Clusters \\
\hline CH & Calinski and Harabasz (1974) [29] & 18.865 & 2 \\
Silhouette & Rousseeuw (1987) [30] & 0.253 & 3 \\
SD index & Haldiki et al. (2001) [31] & 0.635 & 3 \\
Hartigan & Hartigan (1975) [32] & 3.250 & 4 \\
TraceW & Milligan and Cooper (1985) [33] & 49.905 & 5 \\
\hline
\end{tabular}

As evident in Table 2, there was no single best solution for cluster size: the final choice depended on subjective preference and usefulness of the cluster interpretations. Two clusters would provide little practical use, merely creating two polar opposites; five clusters would seemingly be too extensive given the limited dataset. Thus we tested both three- and four-cluster solutions; four clusters provided clearer interpretation and balanced cluster groups. For our cluster method, we adopted hierarchical cluster analysis using squared Euclidean distance intervals and within-group linkages; we followed that with a nonhierarchical k-means clustering method. The Ward method provided largely similar cluster results. Alternative methods (such as between-group linkage, nearest neighbor, furthest neighbor, centroid clustering, and median clustering) all led to at least one cluster with limited (often only one) cases. Table 3 compares cluster assignment according to the two methods. 
Table 3. Cross-tabulation with cluster overlaps.

\begin{tabular}{ccccccc}
\hline & & \multicolumn{4}{c}{ Hierarchical Cluster Analysis } \\
& Cluster & $\mathbf{1}$ & $\mathbf{2}$ & $\mathbf{3}$ & $\mathbf{4}$ & Total \\
\hline & 1 & $8(80.0 \%)$ & $0(0.0 \%)$ & $0(0.0 \%)$ & $0(0.0 \%)$ & $8(19.0 \%)$ \\
k-means cluster & 2 & $2(20.0 \%)$ & $4(66.7 \%)$ & $2(10.0 \%)$ & $1(16.7 \%)$ & $9(21.4 \%)$ \\
analysis & 3 & $0(0.0 \%)$ & $0(0.0 \%)$ & $16(80.0 \%)$ & $0(0.0 \%)$ & $16(38.1 \%)$ \\
& 4 & $0(0.0 \%)$ & $2(33.3 \%)$ & $2(10.0 \%)$ & $5(83.3 \%)$ & $9(21.4 \%)$ \\
& Total & $10(100 \%)$ & $6(100 \%)$ & $20(100 \%)$ & $6(100 \%)$ & $42(100 \%)$ \\
\hline
\end{tabular}

Table 3 clearly indicates that there was significant overlap between the two cluster methods (chi squared $=64.711, d f=9, p<0.000$ ): $80 \%$ of cases assigned to cluster 1 and cluster 3 using the k-means algorithm were also assigned to cluster 1 by hierarchical analysis. For cluster 4 , the proportion was slightly higher $(83.3 \%)$; there was slightly more variation with cluster $2(66.7 \%$ overlap). The cluster solution appeared to be stable and comparable; thus, we used the final cluster centers of the k-means method for thematic analysis of the four generated clusters. The F statistics of the analysis of variance (ANOVA) tests provided an indication as to which areas were particularly relevant in the formation of the clusters: higher scores relating to variables held higher importance in distinguishing between clusters. Only one ANOVA test was nonsignificant: role of university after disaster occurrence. It has to be noted that this nonsignificance is not an indication of lack of general importance of disaster prevention in campus sustainability but merely indicates that the variability in disaster prevention scores did not influence cluster membership assignment. Table 4 provides an overview of the $\mathrm{F}$ statistics and average scores per cluster.

Table 4. Cluster centers and F statistics (based on ANOVA).

\begin{tabular}{|c|c|c|c|c|c|}
\hline Area & Cluster 1 & Cluster 2 & Cluster 3 & Cluster 4 & $\begin{array}{l}\text { F-Statistic } \\
\text { ( } p \text {-Value) }\end{array}$ \\
\hline 1.1 Policy and overall plan & -1.234 & -0.058 & 0.855 & -0.365 & $20.019(0.000)$ \\
\hline 1.2 Organization to consider sustainability & -1.146 & -0.543 & 0.718 & 0.285 & $14.845(0.000)$ \\
\hline 1.3 Financial resource management & -1.295 & -0.285 & 0.850 & -0.075 & $21.395(0.000)$ \\
\hline 1.4 Asset management & -1.211 & 0.176 & 0.702 & -0.348 & $13.294(0.000)$ \\
\hline 1.5 Facility management & -1.198 & 0.196 & 0.595 & -0.190 & $9.737(0.000)$ \\
\hline 1.6 Network to enhance sustainability & -0.890 & -0.256 & 0.773 & -0.327 & $9.392(0.000)$ \\
\hline 1.7 Personnel training & -0.461 & -0.293 & 0.735 & -0.604 & $6.857(0.001)$ \\
\hline 1.8 Procurement and contracts & -0.790 & -0.081 & 0.486 & -0.081 & $3.513(0.024)$ \\
\hline 2.1 Education & -1.107 & 0.050 & 0.546 & -0.037 & $7.011(0.001)$ \\
\hline 2.2 Research & -0.937 & -0.585 & 0.629 & 0.301 & $9.196(0.000)$ \\
\hline 2.3 Students & -1.184 & -0.082 & 0.752 & -0.203 & $12.916(0.000)$ \\
\hline 3.1 Ecosystem & -0.585 & -0.305 & 0.766 & -0.537 & $7.746(0.000)$ \\
\hline 3.2 Land & -0.764 & 0.223 & 0.672 & -0.738 & $9.193(0.000)$ \\
\hline 3.3 Public space & -0.950 & -0.018 & 0.754 & -0.477 & $10.278(0.000)$ \\
\hline 3.4 Landscape & -1.000 & 0.522 & 0.522 & -0.561 & $9.568(0.000)$ \\
\hline 3.5 Waste & -0.373 & -0.865 & 0.761 & -0.156 & $9.264(0.000)$ \\
\hline 3.6 Energy and resources & -1.078 & -0.222 & 0.624 & 0.071 & $8.114(0.000)$ \\
\hline 3.7 Basic equipment & -0.673 & 0.028 & 0.503 & -0.324 & $3.367(0.028)$ \\
\hline 3.8 Facilities & -0.912 & 0.448 & 0.342 & -0.244 & $4.569(0.008)$ \\
\hline 3.9 Transportation & -0.762 & 0.042 & 0.869 & -0.910 & $18.253(0.000)$ \\
\hline 3.10 Use of historical assets on campus & -0.740 & -0.596 & 0.662 & 0.077 & $7.037(0.001)$ \\
\hline $\begin{array}{l}\text { 4.1 Collaboration between industry, academia, } \\
\text { and government }\end{array}$ & -1.306 & -0.049 & 0.525 & 0.278 & $10.693(0.000)$ \\
\hline 4.2 Community service & -1.210 & 0.041 & 0.170 & 0.733 & $8.997(0.000)$ \\
\hline 4.3 Dissemination of information & -1.075 & -0.456 & 0.684 & 0.195 & $10.870(0.000)$ \\
\hline 4.4 Disaster prevention & -0.048 & -0.158 & 0.669 & -0.988 & $8.270(0.000)$ \\
\hline 4.5 Role of university after disaster occurrence & -0.061 & -0.417 & 0.398 & -0.236 & $1.612(0.203)$ \\
\hline
\end{tabular}

Figure 2 provides a graphic profile of each cluster. Cluster $1(n=8)$ combined institutions with limited strategy and implementation of sustainable practices: it scored low for all dimensions. We described this cluster as "lagging behind." By contrast, cluster $3(\mathrm{n}=16)$, which we termed "top of the 
class", was characterized by a larger-than-average level of sustainable practices across fields and areas. The other two clusters showed largely negative values, though there were some exceptions. Cluster $2(\mathrm{n}=9)$, which we described as "asset driven", had high scores in the areas of asset management, facility management, land, landscape, and facilities. Cluster $4(n=9)$, which we termed "networkers", was distinguished by a primary focus on soft approaches to sustainability: outstanding areas here were organization to consider sustainability, research; collaboration between industry, academia, and government; community service, and dissemination of information.

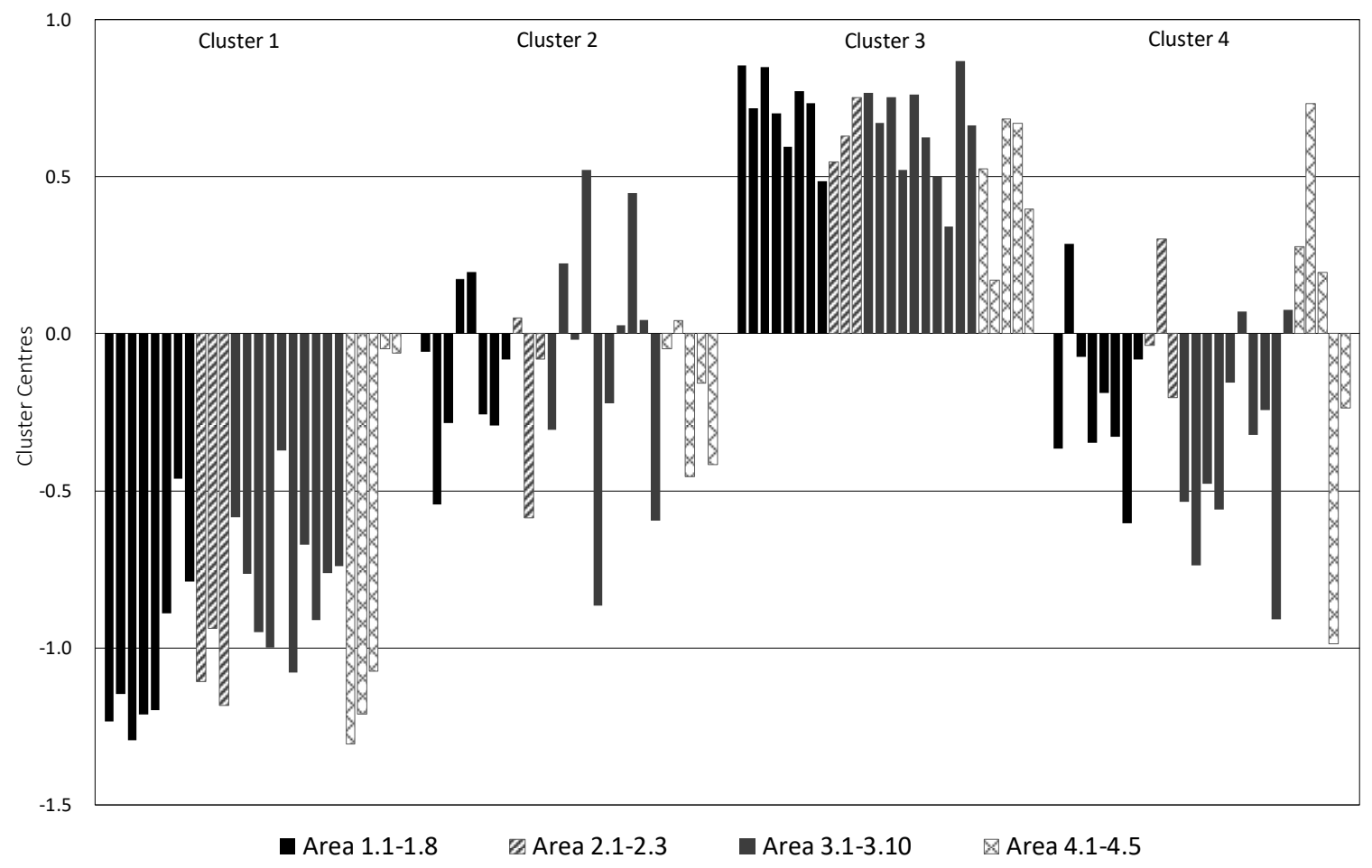

Figure 2. Cluster centers of four defined clusters.

Finally, using discriminant analysis, we tested the quality of the cluster solution; that analysis also provided an answer to the question about which dimensions contributed most to the different clusters [34]. With discriminant analysis, we constructed a model that provided the best assignment of cluster membership based on a linear combination of quantitative predictor variables (i.e., assessment areas) that best predicted group differences. There will always be one less discriminant function than there are groups (in our case, three discriminant functions were generated); thus, we adopted stepwise discriminant analysis. With this stepwise procedure, we found that the canonical discriminant functions $(\mathrm{CDF})$ could be constructed as a linear combination of just five assessment areas:

$$
\begin{aligned}
& C D F_{1}=0.813 x_{1}+0.572 x_{2}+0.361 x_{3}+0.677 x_{4}+0.299 x_{5} \\
& C D F_{2}=-0.856 x_{1}-0.554 x_{2}+1.403 x_{3}-0.554 x_{4}+0.872 x_{5} \\
& C D F_{3}=-0.254 x_{1}+1.070 x_{2}-0.457 x_{3}-0.267 x_{4}+0.180 x_{5}
\end{aligned}
$$

where $\mathrm{x}_{1}=$ financial resource management, $\mathrm{x}_{2}=$ waste, $\mathrm{x}_{3}=$ transportation, $\mathrm{x}_{4}=$ collaboration among industry, academia, and government, and $x_{5}=$ disaster prevention.

The first discriminant function (Equation (1)) had an eigenvalue of 3.160 and explained $64.9 \%$ of the variance. The second function (Equation (2)) had an eigenvalue of 1.429 with an explained variance of $29.3 \%$. The third function (Equation (3)) had an eigenvalue of 0.281 and explained variance of $5.8 \%$. Wilks' lambda suggested that all three linear combinations of predictor variables were significantly 
different among the clusters. However, it was clear from the canonical correlation that Equations (1) and (2) were highly correlated with the clusters (Table 5).

Table 5. Test statistics of three canonical discriminant functions.

\begin{tabular}{ccccc}
\hline & & Function 1 & Function 2 & Function 3 \\
\hline Group centroids & Cluster 1 & -2.440 & 0.928 & 0.618 \\
& Cluster 2 & -0.792 & 0.671 & -0.888 \\
& Cluster 3 & 1.996 & 0.363 & 0.182 \\
& Cluster 4 & -0.587 & -2.141 & 0.015 \\
Eigenvalue & & 3.160 & 1.429 & 0.281 \\
\% variance & & 64.9 & 29.3 & 5.8 \\
Canonical correlation & & 0.872 & 0.767 & 0.468 \\
Wilks' lambda $(p$-value) & & $0.097(0.000)$ & $0.457(0.000)$ & $0.953(0.007)$ \\
\hline
\end{tabular}

Figure 3 indicates how well the discriminant functions were able to separate the different clusters. The discriminant functions were linear combinations of the area variables; thus, Figure 3 provides an indirect answer to the question about the effectiveness of the cluster solution. Figure 3 uses only two of the three discriminant functions; however, those two functions accounted for most of the explained variance $(94.2 \%)$. From the plot in Figure 3, it is apparent that the different observations were quite well separated, with limited overlap between the cluster boundaries. Cross-validation of correctly classified cases based on the derived discriminant function produced promising results. The total proportion of correctly classified cases was $76.2 \%$; in particular, cluster $3(87.5 \%)$ and cluster $1(75 \%)$ were well identified. With the other two clusters, which had less strong profiles, identification was more difficult: $66.7 \%$ of cases were correctly assigned in both cases.

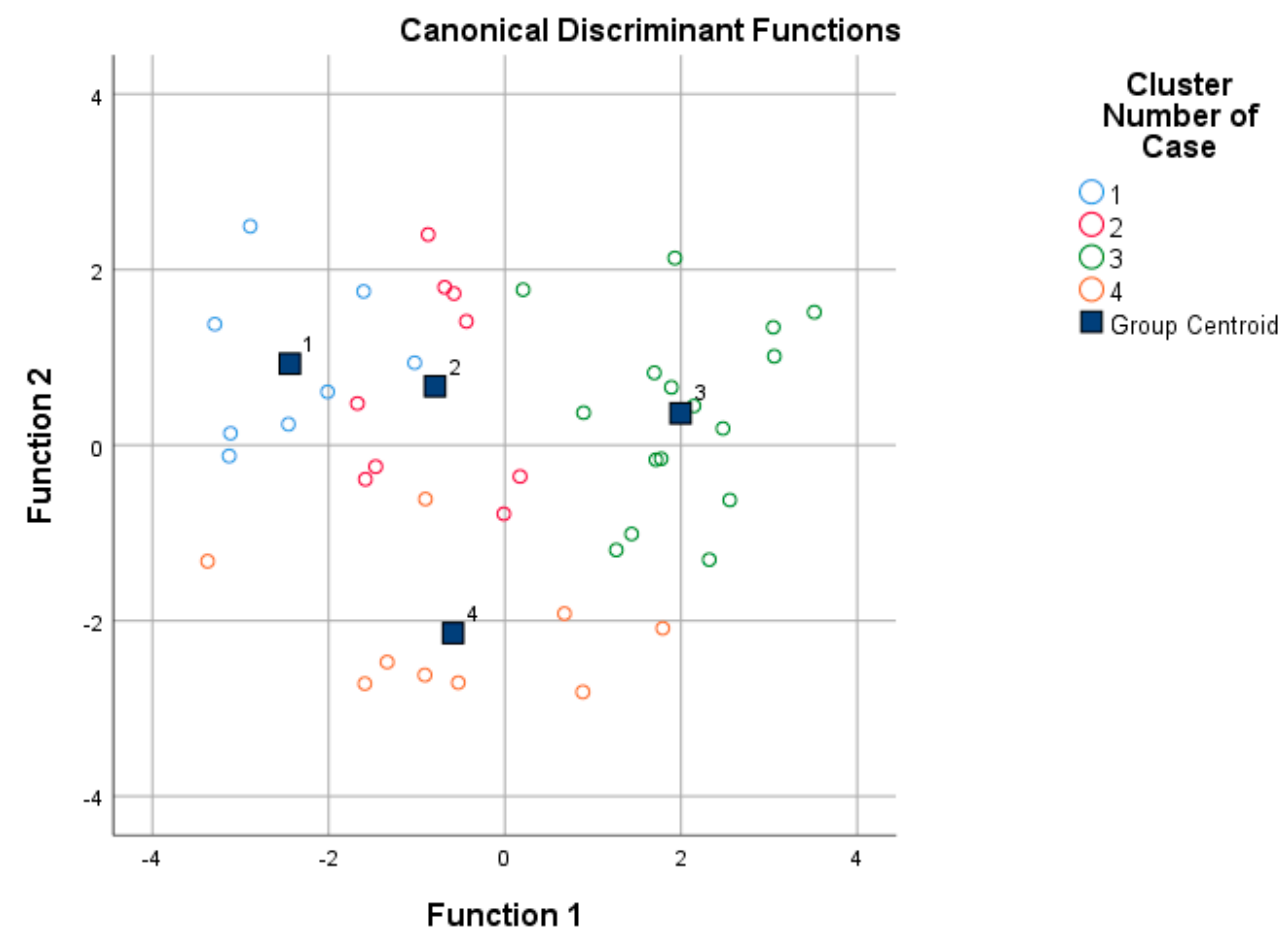

Figure 3. First two canonical discriminant functions. 


\section{Discussion}

As discussed in Section 1.2, Japan's higher education institutions lag behind those in North America and Europe with respect to campus sustainability. It is necessary, therefore, to identify the key factors that support sustainable campus actions in Japan. ASSC has collected information about specific cases of campus sustainability in Japan. From that information, it is possible to identify the respondent institutions that may be regarded as good examples of campus sustainability, allowing an analysis of the crucial factors in the strategy for sustainability.

In this study, we posed the following research question: What are the strategic options of institutions that conform with ASSC? We aimed to identify which fields would be more appropriate for Japanese higher education institutions to begin their campus sustainability actions. Almost no empirical studies have analyzed an extensive number of Japanese cases in this regard. Thus, the results of this study provide a new understanding of how to introduce more institutions to campus sustainability and promote robust growth of such sustainability in Japan.

We used cluster analysis to identify groups of institutions with different strategic options according to their main areas of focus. From the results of our analysis, we were able to identify four groups: lagging behind $(n=8)$; asset driven $(n=9)$; top of the class $(n=16)$; and networkers $(n=9)$. Table 4 and Figure 2 show that the lagging-behind cluster scored low in all areas of ASSC. The top-of-the-class cluster was the opposite: the scores were higher than average in all areas. The findings with the other two clusters (asset driven and networkers) were interesting. Those clusters had largely negative values in most areas; however, each of them had significant positive scores in a particular set of areas (Table 6). All the prominent areas with the asset-driven and networkers clusters were well represented.

Our analysis identified 16 institutions in cluster 3: they adopted a holistic strategic option to pursue all dimensions of campus sustainability and therefore achieved top-of-the-class status. By contrast, the 18 institutions in clusters 2 and 4 were clearly oriented to certain areas of campus sustainability, i.e., asset management or collaboration (networking); they attained higher scores in those dimensions.

Table 6. Areas of ASSC in which the two clusters (asset driven and networkers) had significant positive scores.

\begin{tabular}{cc}
\hline Cluster Name & Area of ASSC \\
& 1.4 Asset management \\
Asset Driven (Cluster 2) & 1.5 Facility management \\
& 3.2 Land \\
& 3.4 Landscape \\
& 3.8 Facilities \\
\hline Networkers (Cluster 4) & 1.2 Organization to consider sustainability \\
& 2.2 Research \\
& 4.1 Collaboration between industry, academia, and government \\
& 4.2 Community service \\
& 4.3 Dissemination of information \\
\hline
\end{tabular}

As discussed in other studies $[25,35,36]$, the general barriers for higher education institutions to integrate sustainability are lack of resources and time. It may be assumed that a large institution could overcome such barriers more easily than a smaller one. We surveyed online the scale of each respondent institution by collecting data about the number of enrolled students. Figure 4 summarizes the distribution of the number of institutions in each cluster according to scale. The three scales are as follows: a small institution had up to 12,000 students; a medium-sized institution had 12,000-24,000 students; a large institution had over 24,000 students. 


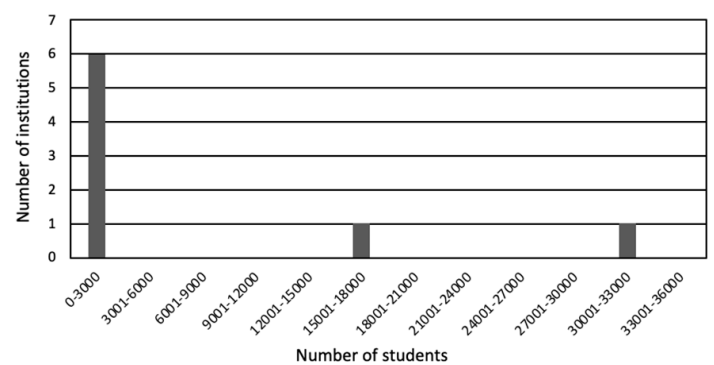

(a)

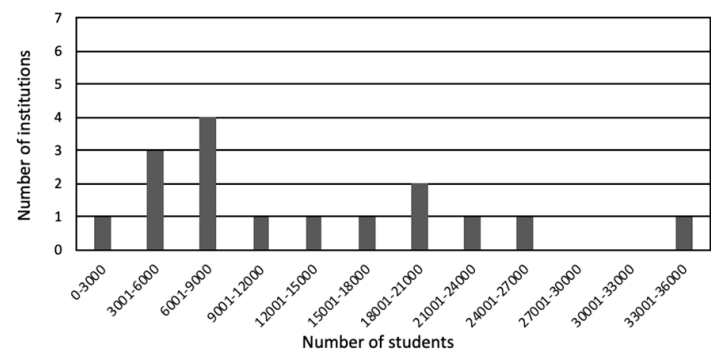

(c)

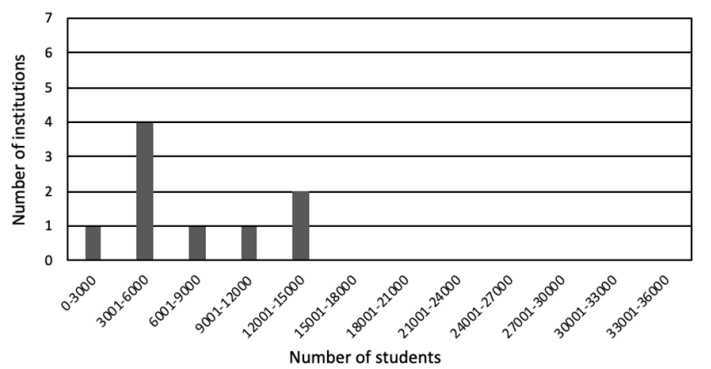

(b)

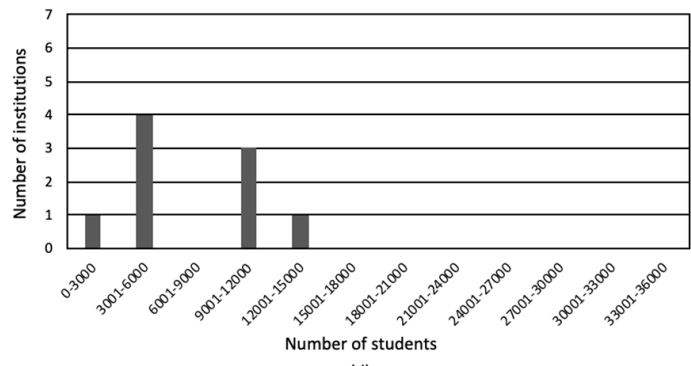

(d)

Figure 4. Distribution of number of institutions in each cluster according to size: (a) cluster 1 (lagging behind); (b) cluster 2 (asset driven); (c) cluster 3 (top of the class); and (d) cluster 4 (networkers). A small institution had up to 12,000 students; a medium-sized institution had 12,000-24,000 students; a large institution had over 24,000 students.

From this survey about the size of institutions, it was clear that small institutions were clearly dominant in the lagging-behind cluster. However, contrary to expectations, small institutions were also well represented in the top-of-the-class cluster: nine small, five medium-sized, and two large institutions. Proportionally, small institutions were less likely to be in the top-of-the-class cluster (nine of 30) than medium-sized (five of nine) or large institutions (two of three); however, it is remarkable that institutions with only 3000-9000 students had sufficient opportunity to perform well in all dimensions of campus sustainability. As indicated in Figure 4, institutions that adopted strategic options for asset management or collaboration tended to be small and medium-sized ones.

With respect to the research question, this study provides two key findings:

1. Both large and small institutions (by adopting holistic strategies) are capable of attaining the top-of-the-class cluster in all dimensions of campus sustainability. Institution size should therefore not be regarded as a limiting factor in pursuing a holistic strategy for sustainability.

2. By focusing on physical campus management or on collaborations between the institution and external bodies, small institutions are capable of promoting their campus sustainability and potentially develop toward a more holistic approach at a later stage.

The present investigation is one of the first empirical studies on campus sustainability in Japan to analyze an extensive number of institutions. Almost no other studies have adopted a similar quantitative approach concerning strategic options in this regard. Thus, our study can offer new general guidance for Japanese institutions wishing to undertake the initiative in campus sustainability.

The performance of ASSC respondent institutions are analyzed in this study based on their score results without investigating social or institutional contexts of universities. This limits the guidance provided here to recommend two fields, physical campus management or collaborations, to be capable of promoting the holistic campus sustainability. To provide more specific guidance, future research should center on providing a more detailed analysis of the following: the content of strategic options; the methods of implementation; and achievements or failures with implementation among each ASSC respondent institution. In some cases, this type of information about institutions has been collected by ASSC; however, those details were not examined in the present study. A further topic of contemporary 
societal interest lies in the role of universities in disaster prevention and management. While elements of institutional disaster prevention are currently measured in the ASSC, this study adopted a higher level clustering approach whereby item-specific in-depth discussions were not part of the current scope. It would be of interest to track the evolution of institutional investment in disaster prevention mechanisms against current events and focus on their role within campus sustainability and resilience. Our future work on campus sustainability will involve, first, investigating such details provided by ASSC. Second, it will be necessary to complement any information not provided by ASSC with on-site investigations, including interviews with staff and students of institutions representing each cluster identified in this study. Only after involving these extensive investigations, the best specific strategies for Japanese higher education institutions will be observed.

Author Contributions: Conceptualization, M.I.; Data curation, B.N.; Formal analysis, B.N.; Funding acquisition, M.I.; Investigation, M.I.; Methodology, B.N.; Project administration, M.I.; Writing—original draft, M.I. and B.N. All authors have read and agreed to the published version of the manuscript.

Funding: This study was supported by JSPS KAKENHI Grant Number JP 19K12438 (Grant-in-Aid for Scientific Research [C]).

Acknowledgments: Data collection by Assessment System for Sustainable Campus (ASSC) is supported by Campus Sustainability Network in Japan (CAS-Net JAPAN). The data concerning individual institutions collected by ASSC is nonpublic. The corresponding author at the Subcommittee for Campus Living Laboratory, Architectural Institute of Japan has the right to access the data since she oversees all the operations of ASSC. The authors would like to thank the secretariat members of CAS-Net JAPAN at Kyoto University, the staff at the respondent institutions, and the members of the Subcommittee for Campus Living Laboratory, Architectural Institute of Japan. We thank Edanz Group (www.edanzediting.com/ac) for editing a draft of this manuscript.

Conflicts of Interest: The authors declare no conflict of interest.

\section{References}

1. Declaration of the United Nations Conference on the Human Environment. Available online: https: //www.un.org/ga/search/view_doc.asp?symbol=A/CONF.48/14/REV.1 (accessed on 29 November 2019).

2. Tbilisi Declaration. Available online: http://www.gdrc.org/uem/ee/tbilisi.html (accessed on 29 November 2019).

3. Olszak, E. Composite indicators for a sustainable campus-Design rationale and methodology: The case of the Catholic Institute of Lille. Ecol. Indic. 2012, 23, 573-577. [CrossRef]

4. Wright, T.S.A. A review of definitions and framework for sustainability in higher education. In Proceedings of the Assessing Progress toward Sustainability in Higher Education Conference, Washington, DC, USA, 29-31 March 2001.

5. Brinkhurst, M.; Rose, P.; Maurice, G.; Ackerman, J.D. Achieving campus sustainability: Top-down, bottom-up, or neither? Int. J. Sustain. High. Educ. 2011, 12, 338-354. [CrossRef]

6. Association of University Leaders for a Sustainable Future, the Talloires Declaration. Available online: http://ulsf.org/wp-content/uploads/2015/06/TD.pdf (accessed on 29 November 2019).

7. Habib, M.A.; Ismaila, A. An integrated approach to achieving campus sustainability: Assessment of the current campus environmental management practices. J. Clean. Prod. 2008, 16, 1777-1785.

8. Waas, T.; Verbruggen, A.; Wright, T. University Research for Sustainable development: Definition and characteristics explored. J. Clean. Prod. 2010, 18, 629-636. [CrossRef]

9. G8 University Summit, Sapporo Sustainability Declaration. Available online: https://eprints.lib. hokudai.ac.jp/dspace/bitstream/2115/65159/5/34_The\%20G8\%20University\%20Summit_The\%20Sapporo\% 20Sustainability\%20Declaration_all.pdf (accessed on 20 November 2019).

10. Cole, L. Assessing Sustainability on Canadian University Campuses: Development of a Campus Sustainability Assessment Framework. Master's Thesis, Royal Roads University, Colwood, BC, Canada, 2003.

11. Velazquez, L.; Munguia, N.; Platt, A.; Taddei, T. Sustainable University: What can be the matter? J. Clean. Prod. 2006, 14, 810-819. [CrossRef]

12. Shriberg, M. Institutional assessment tools for sustainability in higher education: Strengths, weaknesses, and implications for practice and theory. Int. J. Sustain. High. Educ. 2002, 3, 254-270. [CrossRef] 
13. Beringer, A. Campus sustainability audit research in Atlantic Canada: Pioneering the campus sustainability assessment framework. Int. J. Sustain. High. Educ. 2006, 7, 437-455. [CrossRef]

14. Beveridge, D.; McKenzie, M.; Vaughter, P.; Wright, T. Sustainability in Canadian post-secondary institutions-The interrelationships among sustainability initiatives and geographic and institutional characteristics. Int. J. Sustain. High. Educ. 2015, 16, 611-638. [CrossRef]

15. Sonetti, G.; Lombardi, P.; Chelleri, L. True Green and Sustainable University Campuses? Toward a Clusters Approach. Sustainability 2016, 8, 83. [CrossRef]

16. Komiyama, H.; Takeuchi, K. Sustainability science: Building a new discipline. Sustain Sci. 2006, 1, 1-6. [CrossRef]

17. Uwasu, M.; Yabar, H.; Hara, K.; Shimoda, Y.; Saijo, T. Educational initiative of Osaka University in sustainability science: Mobilizing science and technology towards sustainability. Sustain Sci. 2009, 4, 45-53. [CrossRef]

18. Nomura, K.; Abe, O. Higher education for sustainable development in Japan: Policy and progress. Int. J. Sustain. High. Educ. 2010, 11, 120-129. [CrossRef]

19. Kitamura, Y.; Hoshii, N. Education for sustainable development at universities in Japan. Int. J. Sustain. High. Educ. 2010, 11, 202-216. [CrossRef]

20. Bai, Y.; Ikeda, Y.; Ota, S.; Kobayashi, H. Sustainable Campus Initiative at Keio University after the Great East Japan Earthquake Disaster. Int. J. Disaster Risk Sci. 2012, 3, 123-130. [CrossRef]

21. Ueno, T.; Suzuki, M.; Hattori, M.; Sakai, T.; Tsurusaki, N.; Ozasa, T. Environmental Management Model in University intermediating between a campus and a region. In Annual Conference Proceedings, Architectural Institute of Japan; Architectural Institute of Japan: Sapporo, Japan, 2004; pp. 93-96. (In Japanese)

22. Campus Climate Change. Available online: http://ccc.eco-2000.net/eco-campus (accessed on 24 May 2019). (In Japanese).

23. Ueno, T.; Tsurusaki, N.; Ozasa, T.; Tsunekawa, K.; Suzuki, M. Studies on Sustainable Campus Models for Regional Activation. In Annual Conference Proceedings, Architectural Institute of Japan; Architectural Institute of Japan: Tokyo, Japan, 2011; pp. 753-756. (In Japanese)

24. Taira, Y.; Ping, H. Analysis on the relation between SDGs and Campus Master Plan of Hokkaido University. In Proceedings of the Annual Conference of CAS-Net JAPAN, Nagoya, Japan, 23 November 2019. (In Japanese).

25. Lidstone, L.; Wright, T.; Sherren, K. Canadian STARS-Rated Campus Sustainability Plans: Priorities, Plan Creation and Design. Sustainability 2015, 7, 725-746. [CrossRef]

26. Roorda, N. Auditing sustainability in engineering education with AISHE. In Proceedings ENTRÉE 2000; EEE Network: Brussels, Belgium, 2000; pp. 13-30.

27. Sarstedt, M.; Mooi, E. The process, data, and methods using IBM SPSS Statistics. In A Concise Guide to Market Research; Springer: Berlin/Heidelberg, Germany, 2014.

28. Charrad, M.; Ghazzali, N.; Boiteau, V.; Niknafs, A. NbClust: An R package for determining the relevant number of clusters in a data set. J. Stat. Softw. 2014, 64, 1-36. [CrossRef]

29. Calinski, T.; Harabasz, J. A dendrite method for cluster analysis. Commun. Stat. Theory Methods 1974, 3, 1-27. [CrossRef]

30. Rousseeuw, P. Silhouettes: A graphical aid to the interpretation and validation of cluster analysis. J. Comput. Appl. Math. 1987, 20, 53-65. [CrossRef]

31. Halkidi, M.; Batistakis, I.; Vazirgiannis, M. On clustering validation techniques. J. Intell. Inf. Syst. 2001, 17, 107-145. [CrossRef]

32. Hartigan, J.A. Clustering Algorithms; John Wiley \& Sons, Inc.: New York, NY, USA, 1975.

33. Milligan, G.W.; Cooper, M.C. An examination of procedures for determining the number of clusters in a data set. Psychometrika 1985, 50, 159-179. [CrossRef]

34. Madrigal, R. Residents' perceptions and the role of government. Ann. Tour. Res. 1995, 22, 86-102. [CrossRef]

35. Karatzoglou, B. An in-depth literature review of the evolving roles and contributions of universities to Education for Sustainable Development. J. Clean. Prod. 2013, 49, 44-53. [CrossRef]

36. Krizek, K.J.; Newport, D.; White, J.; Townsend, A.R. Higher education's sustainability imperative: How to practically respond? Int. J. Sustain. High. Educ. 2012, 13, 19-33. [CrossRef]

(C) 2020 by the authors. Licensee MDPI, Basel, Switzerland. This article is an open access article distributed under the terms and conditions of the Creative Commons Attribution (CC BY) license (http://creativecommons.org/licenses/by/4.0/). 